\title{
A abordagem da teoria dos conjuntos em dois livros didáticos utilizados no ensino secundário na Bahia durante a década de 1970: uma análise histórica das teorias modernas da matemática
}

\author{
Alice Mascarenhas Oliveira \\ 1. Bolsista PIBIC/CNPq, Graduanda em Licenciatura em matemática, Universidade Estadual de Feira de Santana, \\ e-mail: alice.11@hotmail.com.br \\ 2. Eliene Lima Barbosa, Ciências Exatas (DEXA), Universidade Estadual de Feira de Santana, e-mail: \\ elienebarbosalima@gmail.com
}

\begin{abstract}
PALAVRAS-CHAVE: Livro Didático; Teoria dos Conjuntos; Teorias Modernas da Matemática.
\end{abstract}

\section{INTRODUÇÃO}

A pesquisa teve como objetivo, analisar as similitudes e diferenças da abordagem da teoria dos conjuntos em dois livros didáticos utilizados no ensino secundário na Bahia durante a década de 1970. Este trabalho científico está inserido no projeto de pesquisa intitulado "As teorias modernas da matemática nos livros didáticos das instituições educacionais superiores e secundárias brasileiras e baianas", que visa "[...] investigar anatomicamente, numa perspectiva histórica, as teorias modernas da matemática nos livros didáticos apropriados, produzidos e difundidos no âmbito do ensino superior e secundário brasileiro, em especial na Universidade de São Paulo (USP) e na Bahia, no período de 1934 até aproximadamente 1976 [...]" (LIMA, et. al, 2013).

A modernização da matemática foi consolidada no século $\mathrm{XX}$, mas seu processo de mudanças e transformações se deu no século anterior, resultando em novas álgebras, novas axiomáticas e a teoria dos conjuntos. (LIMA et. al, 2010). Essa modernização foi apropriada no âmbito das escolas secundárias em dois momentos diferentes, porém para desenvolvimento desta pesquisa foquei particularmente na segunda reformulação, que ocorreu pós-segunda guerra mundial. Tal reformulação, ocorrida em países europeus e americanos em especial nos Estados Unidos, ficou conhecida posteriormente como Movimento da Matemática Moderna (MMM). Este movimento tinha como finalidade tornar o ensino secundário de matemática mais próximo do seu ensino a nível superior. O Grupo Bourbaki foi um dos influenciadores para esta reformulação, na medida em que apresentaram sua axiomática estruturalista argumentado a partir dos conceitos de raciocínio dedutivo, formalismo lógico e método axiomático. Para o Grupo Bourbaki, conforme Lima (2012), o raciocínio dedutivo, seria uma espécie de "linguagem" utilizada pelos matemáticos para a comunicação e formalismo lógico seria as "regras desta linguagem", numa perspectiva pouco relevante do método axiomático. Assim, para o Grupo o método axiomático serviria para entender os motivos das descobertas dessas teorias e tornar suas ideias mais esclarecidas. No Brasil, o MMM foi apropriado, principalmente pelos grupos de estudos em diferentes estados brasileiros, dentre eles, destaco o Grupo de Estudo da Matemática (GEEM) em São Paulo, tendo como presidente o professor Osvaldo Sangiogi e o grupo de professores da Bahia, vinculado à Seção Científica de Matemática do Centro de Ensino de Ciências da Bahia (CECIBA) liderado por Martha Maria de Souza Dantas e Omar Catunda, ambos professores da Universidade Federal da Bahia (UFBA). Estes grupos realizavam palestras, cursos de atualização e produziam livros, para apresentar as ideias do MMM, visando uma apropriação dos professores que lecionavam no âmbito escolar. 
Um dos livros selecionados para a construção desta pesquisa foi o Ensino Atualizado de Matemática, da quinta série do primeiro grau, produzido após o encerramento do CECIBA, orientado por Omar Catunda (1906-1986), sob autoria de Martha Maria de Souza Dantas (1925-2011), Eliana Costa Nogueira, Norma Coelho de Araújo, Eunice da Conceição Guimarães, Neide Clotilde de Pinho e Souza e Maria Augusto de Araújo Moreno, todos membros do grupo. Ele corresponde a $3^{\text {a }}$ edição, sendo publicado pela São Paulo Livraria Editora Limitada (EDART), no ano de 1974. O outro livro foi Matemática 5, $3^{\text {a }}$ edição, destinado a primeira série do antigo curso ginasial , com autoria de Osvaldo Sangiorgi (1921-2017), publicado em 1973, pela Companhia Editora Nacional. Dessa forma, ambos os livros didáticos, utilizados no ensino baiano, foram produzidos por professores com participações ativas em grupos de estudos que tiveram papel relevante no período de uma modernização da matemática secundária no contexto brasileiro.

Entendeu-se aqui como livro didático “(...) um instrumento de comunicação, de produção e transmissão de conhecimento (...)" (BITTENCOURT, 2004, p.1), assumindo funções variadas no contexto escolar a depender do local onde é utilizado e do período em que foi produzido. A pesquisa histórica sobre livros e edições didáticas aborda diversos aspectos, com isso Choppin (2004) lista duas categorias de pesquisa, a que os historiadores utilizam os livros didáticos, sem que sejam excludentes entre si: a primeira, como documento histórico, analisando os seus conteúdos, nesse caso a história que os pesquisadores apresentam é de um tema, de uma disciplina ou de que modo o livro era utilizado em sala de aula; a segunda, como objeto físico, onde o historiador foca "[...] sua atenção diretamente para os livros didáticos, recolocando-os no ambiente em que foram concebidos, produzidos, utilizados e 'recebidos', independentemente, arriscaríamos a dizer, dos conteúdos dos quais eles são portadores." (CHOPPIN, 2004, p. 554). Foi, portanto, sob essa ótica que analisei os dois livros didáticos utilizados no ensino secundário na Bahia durante a década de 1970.

\section{MATERIAL E MÉTODOS OU METODOLOGIA (ou equivalente)}

Para esta pesquisa, de caráter histórico, foram escolhidos, principalmente, como referenciais teórico- metodológicos, para tratar de livros didáticos, textos de Choppin (2004) e Bittencourt (2004), bem como o texto de Guimarães (2007) sobre modernização do ensino secundário da matemática. Para as discussões e sínteses dos textos foram realizadas reuniões individuais com a minha orientadora, bem como por meio da minha participação no Grupo de Pesquisa Laboratório de Integração e Articulação entre Pesquisas em Educação Matemática e Escola (LIAPEME). A escolha e a localização dos livros foi outro passo para o desenvolvimento da pesquisa. O livro Ensino Atualizado da matemática, de Catunda et al. foi acessado facilmente na biblioteca Central Julieta Carteado da Universidade Estadual de Feira de Santana (UEFS) e o Matemática 5, de Sangiorgi, foi necessário solicitar em uma loja virtual. Além dos livros, identifiquei os seus respectivos guias do professor, sendo que um deles, referente ao livro de Catunda et al, foi disponibilizado pela a professora Eliene Lima e, o outro, correspondente ao livro de Sangiorgi, por meio do contato com o Grupo de Pesquisa de História da Educação Matemática (GHEMAT) em São Paulo, adquirindo também o seu caderno de exercício. Para a análise destes livros, fiz uma tabela, dividida em duas colunas, nas quais descrevi suas respectivas estruturas e a forma como os conteúdos foram apresentados.

\section{RESULTADOS E/OU DISCUSSÃO (ou Análise e discussão dos resultados)}


Como já mencionei anteriormente, este trabalho analisou dois livros didáticos - Ensino Atualizado de Matemática de Catunda et. al e Matemática 5 de Osvaldo Sangiorgi publicados na década de 1970, focando na abordagem da teoria dos conjuntos. Na capa do livro de Catunda et al., está presente o título alinhado à esquerda no canto superior, a série ao qual o livro está destinado, nome da editora e uma representação de figuras geométricas planas postas uma sobre a outra ao lado direito dos nomes dos autores. $\mathrm{O}$ livro possui representações, como diagramas e tábuas, além disso, os exercícios são distribuídos ao final dos tópicos de cada capítulo. Por sua vez, o livro de Sangiorgi apresenta na capa o título, nome do autor e a série a qual o livro está destinado, tudo centralizado na parte inferior e, como plano de fundo, uma imagem de um professor de costas escrevendo no quadro. Para além de diagramas, gráficos e tábuas, o livro apresenta outras ilustrações mostrando o cotidiano dos alunos. Contudo, ele não possui exercícios, mas acompanha um caderno apenas para este fim. Para a definição de conjunto, o livro de Catunda et al. apresenta inicialmente exemplos do cotidiano, fazendo uso dos substantivos coletivos - ramalhete, enxame, constelação e outros - e deixa uma observação: "Para ser tratado matematicamente, um conjunto deve ser constituído de elementos bem caracterizados." (CATUNDA et al., 1974, p.7). Por sua vez, no livro de Sangiorgi, a definição de conjunto segue uma linguagem mais próxima da realidade: "Toda coleção de objetos, pessoas, animais, ou coisas constitui um conjunto." (SANGIORGI, 1973, p.2). O autor traz exemplos com diagramas e faz indagações com o intuito de instigar o aluno a refletir. No livro de Catunda et al., os autores apresentam uma seção voltada exclusivamente para as estruturas algébricas, estruturas essas que foram definidas a partir de operações, fazendo uso das seguintes propriedades: fechamento, comutativa, associativa e existência de elemento neutro e simétrico. Já no de Sangiorgi, o autor não aborda essas estruturas, mas apresenta as propriedades quando abordou o conjunto dos números naturais e suas operações em outro tópico.

\section{CONSIDERAÇÕES FINAIS (ou Conclusão)}

Diante das análises apresentadas, concluí que apesar dos dois livros se apropriarem da reformulação do ensino secundário de matemática, eles não foram produzidos sobre uma mesma perspectiva. No livro de Catunda et.al, interpretei que há um direcionamento para uma formalização matemática, isto é, inicia o conteúdo numa linguagem próxima do cotidiano, mas que, paulatinamente, buscou-se uma linguagem lógico-dedutiva da matemática, com o uso, de forma significativa, de suas simbologias. Quando os autores apresentaram a intersecção de conjuntos, eles consideraram inicialmente dois conjuntos com palavras comuns da realidade do aluno correspondendo os elementos, em seguida, traz o símbolo de intersecção, a representação gráfica por meio do diagrama de Venn e uma notação generalizada da situação. "De um modo geral, dados dois conjuntos $\mathrm{X}$ e $\mathrm{Y}$, tem-se $\mathrm{X} \cap \mathrm{Y}=\{\mathrm{x}$ tais que $\mathrm{X}$ $\in \mathrm{X}$ e $\mathrm{x} \in \mathrm{Y}$ \}." (CATUNDA et al., 1974, p.13).

Por sua vez, o livro de Sangiorgi, tem também uma apresentação do conteúdo a partir da realidade do aluno, contudo, pareceu-me que buscou ilustrar as situações problemas sem se preocupar tanto com o formalismo matemático, Para tratar do conteúdo de correspondência biunívoca o livro de Catunda et al. trás dois conjuntos com cidades e estados respectivamente como elementos e outros dois exemplos de conjuntos com números, a partir daí segue com um texto explicando o que seja uma correspondência biunívoca. Diferentemente, o livro de Sangiorgi, aborda este mesmo assunto, somente com situações familiares e ilustrações da realidade do aluno. Assim, na minha ótica, o livro de Sangiorgi seguiu, mais fortemente, os princípios da escola novista, no qual “(...) o ensino deveria pautar-se pela integração das matérias e ser estimulado por 
questões de interesse geral dos alunos, partindo de sua realidade mais próxima." (VIDAL, 2003, p.511). Por outro lado, ambos os livros trabalharam as teorias da matemática de forma interdisciplinar. Nesse movimento de análise, despertei o interesse em discutir quais eram as orientações metodológicas que os autores recomendavam aos professores para ensinar as teorias dos conjuntos em seus respectivos guias.

\section{REFERÊNCIAS}

BITTENCOURT, Circe Maria Fernandes. Em foco: história, produção e memória do livro didático. Educação e Pesquisa, São Paulo, v.30, n. 3, [n.p], set./dez. 2004.

CATUNDA, Omar et al. Ensino atualizado da matemática: $5^{\text {a }}$ série, $1^{\circ}$ grau. 3 . ed. rev. São Paulo: EDART, 1974.

CHOPPIN, Alain. História dos livros e das edições didáticas: sobre o estado da arte. Educação e Pesquisa, São Paulo, v.30, n. 3, p. 549-566, set./dez. 2004. Disponível em: < http://www.scielo.br/pdf/ep/v30n3/a12v30n3.pdf>. Acesso em: 16 fev. 2011.

GUIMARÃES, Henrique Manuel. Por uma Matemática nova nas escolas secundárias: perspectivas e orientações curriculares da matemática moderna. In: MATTOS, José Manuel; VALENTE, Wagner Rodrigues. (Org.) A Matemática Moderna nas escolas do Brasil e de Portugal: primeiros estudos. São Paulo: GHEMAT, 2007.

LIMA, Eliene Barbosa; LANDO, Janice Cássia; FREIRE, Inês Angélica Andrade. A Coleção Didática Ensino Atualizado da Matemática: o guia do professor. In: CONGRESSO IBEROAMERICANO DE EDUCACIÓN MATEMÁTICA, 7, 2013. Actas..., Montevidéu, Uruguai, 2013.

LIMA, Eliene Barbosa. Matemática e matemáticos na Universidade de São Paulo: italianos, brasileiros e bourbakistas (1934-1958). 2012. 260f. Tese (Doutorado em Ensino, Filosofia e História das Ciências) - Instituto de Física, Universidade Federal da Bahia/Universidade Estadual de Feira de Santana, Salvador, 2012.

LIMA, Eliene Barbosa et al. A institucionalização da matemática moderna nos currículos escolares ou a hegemonia da cultura matemática cientifica nas escolas. In: JORNADAS LATINOAMERICANAS DE ESTUDIOS SOCIALES DE LA CIENCIA Y TECNOLOGIA, 8., 2010, Buenos Aires. Anais... [S.I.: s.n], 2010, 1CD ROM, p. 119.

SANGIORGI, Osvaldo. Matemática 5: volume correspondente à $1^{\mathrm{a}}$ série do antigo ginasial. 3. ed. São Paulo: Companhia Editora Nacional, 1973.

VIDAL, Diana Gonçalves. Escola Nova e processo educativo. In: LOPES, Eliane Marta, FIGUEIREDO, Luciano e GREIVAS, Cynthia (Orgs.). 500 anos de educação no Brasil. 3 ed. Belo Horizonte: Autêntica, 2003. 